\title{
Construction of Business Administration Practice Course Based on Intelligent Business Analysis
}

\section{Chengyan Cheng}

Nanchang Institute of Science \& Technology, Nanchang, Jiangxi, 330108

Keywords: intelligent business; business administration; practical course

\begin{abstract}
With the continuous development and progress of the times, the past business management practice courses have been unable to meet market demand. In recent years, China has made continuous breakthroughs in the direction of big data and made remarkable progress. Traditional business draws on the development of big data, and it has become a trend to move closer to the direction of intelligence. As a result, business intelligence (BI) has emerged. Business intelligence (BI) is essentially a new technology that captures the information needed from big data, integrates the extracted information, and refines the knowledge points to help and support decision making. In order to comply with the development of the times, in the education of our country, the business management practice curriculum must be reformed, and a new business management practice course based on intelligent business analysis must be built. This paper explores the difficulties and outlets of this new business management practice class.
\end{abstract}

\section{Introduction}

With the development of China's education, the original graduation of college students is equal to the mode of job-seeking, and now it no longer exists. Therefore, it is especially important to carry out practical courses to lead students to feel the working atmosphere in advance and to carry out social practice. The practical curriculum is also a way for the country to train talents. Through the practice of content, it helps students to understand the new trends and new content of the industry, help students to learn professional knowledge and understand the social content corresponding to the profession. The country hopes that the role of college students after graduation is not only a job seeker, but also a pioneer of the new era. Nowadays, the basic content of business administration is more delivered to BI technology for analysis. Therefore, the corresponding business management practice courses must also follow up, introduce business intelligence into the classroom, and build a new business management practice course based on intelligent business analysis.

\section{The Content and Characteristics of Business Intelligence}

Business intelligence is a technology that uses data warehouse, data refinement, data analysis and other support systems to collect, integrate, refine, and analyze large amounts of data and information generated during the business process. This method can give the most effective information to the enterprise, facilitate the rapid understanding of the employees, make timely and correct decisions, and adopt effective business actions. Therefore, business intelligence significantly improves the company's business operation efficiency, speeds up the response, optimizes business processes, and shortens the production cycle. It is a booster for companies to improve their performance. Compared with ordinary enterprises, business intelligence enterprises have more flexible business functions and stronger competitiveness, and have greater advantages in the business market.

\section{The Problem in Intelligent Business of Business Management Practice Courses}

There are different levels of problems in the practical courses of many business management companies. For example, the curriculum is unreasonable, the content of the course is too broad, and 
the economy, computer, management, etc. are involved. The scope of hunting is too broad, and all aspects of basic knowledge are known, but the degree of mastery of professional knowledge is insufficient. With the specificization of the division of labor in modern enterprises, the practice courses of this kind of multi-faceted approach are not professional, the advantages are not outstanding, and there is not enough professional competitiveness to meet the actual requirements of enterprises. On the other hand, the goal of training in practical courses is not clear, and the original positioning of business administration is management and supervision. However, in the course of practicing the curriculum, the curriculum lacks characteristics, the positioning are not clear, and the phenomenon of plagiarism is serious. The talents cultivated in the practical curriculum lack creativity, do not have the subjective ability, analyze and solve problems unsatisfactory, and the ability to organize and coordinate the various departments of the company is even more unfamiliar, and the business administration profession is seriously inconsistent. Finally, the practical content of the practical class is empty, and the overall is the explanation of theoretical knowledge. The participation of the learners is low, the enthusiasm is not strong, and the ability to be independent is lacking. The practice content deviates from the actual operation of the enterprise, and does not penetrate the core of all aspects of the enterprise. The participants do not understand the corporate culture and have weak execution ability. In general, the practice content is empty and the effect is not obvious.

Business intelligence requires a multitude of big data talents, including system developers, data analysts, and big data application developers. Applying big data to business operations is different from the previous business model. It requires big data builders to have outstanding capabilities in many aspects. It is a position where a compound talent can take office. First, big data analysts need to collect and store effective information about corporate business activities, integrate and refine the data information, and need to master a variety of effective data analysis methods, and can apply the corresponding data analysis methods to practical cases. This tested the analyst's specific technical capabilities and data analysis capabilities. Secondly, data analysts also need to master the use of various tools, face the huge database, put theoretical knowledge into business management, need to apply various data analysis tools, but also use SAS, SPSS, Exccl And other professional related software. Then, the premise of the data analyst's analytical work is to understand the business business, familiar with the industry market and the overall process of business operations. If it is separated from the actual industry knowledge and the company's business background, it is not practical to talk about the data analysis. There is no commercial reality. Finally, the analyst also needs to use visual tools such as charts to visually and effectively express and display the direction and results of the data analysis. The graphical tables are combined and the results are analyzed. This way of combining charts requires designers to master basic office software, mastering certain programming skills and art skills.

\section{The Solution to the Intelligent Business of Business Management Practice Courses}

Modern enterprises are fiercely competitive, and it is difficult for companies to survive in a commercial society without a skill. The application of big data to business management can facilitate enterprises to judge the future direction of economic development and predict the future direction of the industry. It is expected in advance whether the enterprise needs reform and transformation, pre-read the relevant national policies, understands relevant laws, and prepare for the future. Because of this convenience, companies need big data analysts. However, the professional requirements of big data engineers are high, and it is difficult for existing employees of the company to learn by themselves and meet the requirements of analysts. Therefore, companies need to hire big data analysts to meet the daily needs of the company. At the same time, enterprises can adopt the "old and new" model and implement the model of introducing new talents to lead the old employees to learn. Over time, the number of employees who master big data analysis methods has increased, and corporate business activities have become more convenient. At the same time, it is necessary to pay attention to the main points of applying big data, and this knowledge should be explained in the first place. The first is the integrated teaching of data. In the face of a huge 
database, how to accurately and effectively analyze the data needed for the business operation of enterprises is particularly important. With reference to the recent national conditions in China, the credit information of enterprises also needs to be counted and publicized. This improves the information utilization rate, and the credit level of the enterprise also constitutes a common regulatory mechanism of the country, which is conducive to the unification of business administration.

To cultivate practical talents applicable to enterprises, we must abandon old ideas and original teaching models. The modern economic industry is developing stably and making rapid progress. The competition between enterprises is more intense and the cooperation is becoming close. The business management talents need to cooperate with various companies to complete the cooperation tasks and projects between the cooperative companies. In the process of cultivating business management talents, practical courses need to keep pace with the times and add new content needed for enterprise development. The practical curriculum should be more practical, go deep into each company, understand the corporate culture and cooperation model of different companies, and compare the similarities and differences between the major enterprises in management cooperation. The similarities of major companies are often the core content of enterprise development. Different points should be analyzed according to the specific functions of the company, and the management methods that are suitable for the company can be formulated. On the other hand, to enhance the professionalism of practical courses, business managers should have an in-depth understanding of the company's information in all aspects. Nowadays, the development and popularization of the Internet is not as difficult as it used to be. Business management can fully understand the corporate information through the Internet. The business management personnel trained by the enterprise should have sufficient familiarity with the enterprise and master their own deeper high-end knowledge, so that the development of the enterprise can continue to grow. The content can be modified reasonably and effectively, and the content adaptability is stronger, and the business intelligence of the business management course can be solved.

\section{Conclusion}

The main source of economic growth in China is the commercial progress of major enterprises. Therefore, the work of business administration must follow the development of the enterprise and keep pace with the times. In order to adapt to the current "Internet + " era, to cater to the market form, to increase the role of business management in enterprises, to bring more stable upside for economic development, the construction of business management practice courses based on intelligent business has certain necessity.

\section{References}

[1] Chen Changbin, Sheng Xin. Construction of core curriculum resource construction system for business administration majors: based on the integration of innovation and practice [J]. Value Engineering, 2018, 37 (15): 273-276.

[2] Zheng Baohua. Research on the Diversified Evaluation of the Practice Teaching Courses of Business Administration Based on the Extension Model[J].Industry and Technology Forum,2018,17(08):62-64.

[3] Liu Fang, Long Haijun, Peng Yu. Optimization of the Curriculum System of Business Administration Based on the Cultivation of Students' Practical Ability— Taking Jishou University as an Example [J]. Contemporary Education Practice and Teaching Research, 2016(05): 53- 54.

[4] JIN Mei, ZHANG Kai, YUAN Jinlong.The Construction of Business Administration Curriculum System Based on the Core of Entrepreneurial Ability[J].Economic Research Guide, 2013 (09):293-294.

[5] LIU Yan, LI Xi-feng, LI Hong-wei. Research and Practice on Teaching Reform of Business Administration Majors in Open Education [J]. Journal of Shaanxi Radio \& TV University, 2011, 13(01): 18-22. 